\title{
Correction to: Evaluation of Nexus-Sustainability and Conventional Approaches for Optimal Water-Energy-Land-Crop Planning in an Irrigated Canal Command
}

\author{
Aurobrata Das ${ }^{1} \cdot$ Bhabagrahi Sahoo $^{1} \cdot$ Sudhindra N. Panda ${ }^{2,3}$ \\ Published online: 14 July 2020 \\ (C) Springer Nature B.V. 2020
}

\section{Correction to: Water Resour Manag \\ https://doi.org/10.1007/s11269-020-02547-y}

The original version of this article unfortunately contains mistake in equation 9. The mistake and correction is described below:

$$
\mathrm{NSI}=\left(\prod_{\mathrm{i}=1}^{\mathrm{n}} \mathrm{w}_{\mathrm{i}} \mathrm{DI}_{\mathrm{i}}\right)^{1} / \mathrm{n} \text { should be NSI }=\left(\prod_{\mathrm{d}=1}^{\mathrm{n}} \mathrm{DI}_{\mathrm{d}}\right)^{1 / n}
$$

Publisher's Note Springer Nature remains neutral with regard to jurisdictional claims in published maps and institutional affiliations.

The online version of the original article can be found at https://doi.org/10.1007/s11269-020-02547-y

Bhabagrahi Sahoo

bsahoo2003@yahoo.com; bsahoo@swr.iitkgp.ac.in

Aurobrata Das

dasaurobrata@gmail.com

Sudhindra N. Panda

sudhindra.n.panda@gmail.com

1 School of Water Resources, Indian Institute of Technology Kharagpur, Kharagpur 721302, India

2 National Institute of Technical Teachers Training and Research (NITTTR), Taramani, Chennai, Tamilnadu, India

3 Agricultural and Food Engineering Department, Indian Institute of Technology Kharagpur, Kharagpur 721302, India 